\title{
The Application of MBTI to Analyze EFL Teachers' Teaching Styles
}

\author{
Fajar Riyantika ${ }^{1}$, Gita Hilmi Prakoso ${ }^{2}$, Dian Shafwati ${ }^{3}$, Lilis Sholihah ${ }^{4}$ \\ \{fajarriyan87@gmail.com ${ }^{1}$, gitahilmi@gmail.com ${ }^{2}$, dianshafwati@fkip.unila.ac.id ${ }^{3}$, \\ lilissholihah1986@gmail.com ${ }^{4}$ \} \\ Lampung University, Bandar Lampung, Indonesia ${ }^{1234}$
}

\begin{abstract}
Recent data from previous studies show correlation between EFL teachers' teaching style and their personality types. This study was intended to analyze the significance of personality types in English teachers' style of teaching. The personality types used in this study are based on mental functions namely intuition, thinking, feeling and sensing, driven by orientation of energy based on introverted and extroverted traits. The Myers-Briggs Type Indicator (MBTI) is a commonly used instrument to identify personality types. Population of this study was English teachers at senior high school level. Responses to a survey regarding teaching style of 75 English teachers in Lampung were taken to obtain point of view regarding personality types and preference in applying teaching approach. The findings reveal that personality types based on MBTI are significantly correlated with EFL teachers' teaching style. Finally, it can be identified that personality types influence preferences and beliefs in applying teaching style.
\end{abstract}

Keywords: Myers-Briggs Type Indicator (MBTI), teaching style, personality, mental functions, EFL teachers.

\section{Introduction}

A large body of data concerning personality types and psychological factors has been reported to be influential in driving someone to make decision and build habits. In their descriptive case study, Russel and Avgerinou explored MBTI personality preferences of university teachers, as reflected in online teaching and learning situation. They classified personality preferences of the teachers and identified how each type of personalities affected students' learning experience and found that contrasting personalities between teachers and students caused some misunderstandings during teaching process. Despite the result of a specific previous study that confirmed the effect of different personalities in teaching and learning, Russel and Avgerinou stated that deeper analysis and further study was required to fully understand the correlation between personality types and teaching styles [1]. Further, a study specifically designed to analyze EFL teachers' personality types in relation to their teaching style might fill some gaps and enrich the understandings regarding personalities and teaching preferences issue.

Myers developed the concept of 16 personality types based on the theory of Carl Jung's Mental Function. Until recently, those types are indicated by the instrument called MBTI. Unlike the common perceptions about extraversion and introversion traits, Myers also stated that the concept of personality is extraordinarily dynamic and includes not only the direction of energy known as extrovert and introvert qualities, but also some mental processes such as thinking, feeling, sensing, and the use of intuition. These mental functions are stacked in such a 
systematic way known as the dominant function, auxiliary function, tertiary function, and inferior function [2].

More specifically, Myers mentions that each type has acronym based on its organized mental functions known as four MBTI dichotomies; Extraversion-Introversion Dichotomy (attitudes or orientations of energy), Sensing-Intuition Dichotomy (functions or processes of perceptions), Thinking-Feeling Dichotomy (functions or processes of judging), JudgingPerceiving Dichotomy (attitudes or orientations to the outside surroundings). The combinations of those functions create 16 different personality types with stacked dichotomies that drives each of them. For instance, ENTP is named based on its dominant extroverted intuition function $(\mathrm{Ne})$, introverted thinking function $(\mathrm{Ti})$ and combination of extroverted feeling and introverted sensing that creates perceiving quality. These functions, according to Myers might shift and altered based on the needs and emotional states of the individual [2].

Regarding the versatility of personality types by Myers, several research studies have been done to see the connection between the 16 types of personality and several aspects in life, including the teaching and learning. Some researchers found that the application of MBTI and the characterization of 16 personalities played significant role in the field of education, as well as in English Language Teaching.

Kise applied problem-solving approach to help teachers identifying changes in their students' performance. The result of her study showed that different personality types significantly influential in the decision making and action taking of teachers [3].

Another study by Rushton et al. examined the connection among heterogeneous College of Education programs selected by pre-service teachers and their personality attributes. The study provided the assessment results of 368 pre-service teachers in 5 different programs using MBTI [4]. Based on the results, different groups of different programs favored different mental functions. It implied that heterogeneous population may have different preferences in the use of mental functions of MBTI.

Behnam and Bayazidi investigated the relation between personality types of Iranian EFL teachers and their teaching styles in IELTS preparation class of adult EFL learners [5]. 40 teachers were involved and the result showed neither personality types nor other aspects such as gender or age affected teaching styles significantly. However, another study by Atlan explored the valuable potential of MBTI for identifying effective teachers. He conducted MBTI assessment for pre-service ELT teachers and found out $73 \%$ of the participants had the extroverted orientation energy with ENFJ as the most common types within 56 participants. According to Atlan, pre-service ELT teachers with the orientation of extroverted energy were more dominant as they could lead a group efficiently [6]. This study, in line with some previous ones, approved the positive influence of personality identification in EFL teaching and learning.

This study focused on analyzing the teaching styles of EFL teachers and their preferences in utilizing media by applying Myers-Briggs Types Indicators (MBTI). The aim of this study was to analyze and explain the significance of understanding personality types among English teachers in senior high school level, and its relation to their preferences in deciding teaching strategies and choosing media to use. Regarding the objective, the following research question is proposed:

Do teachers' teaching strategies and use of media show significant differences based on their personality types? 


\section{Methodology}

\subsection{Participants}

This study took place in Lampung and involved the population of English language teachers at the senior high school level. Senior high school teachers were chosen since the subjects of English language were widely, and actively, encouraged in that particular level of education in Indonesian Curriculum. Further, language teachers in senior high school level were required to involve more interactive techniques and media in the process of their teaching. 75 English teachers from varied senior schools and non-formal educational institution such as English courses were targeted to participate in this study as they were included in a survey and in-depth interview.

\subsection{Instruments}

The participants completed a questionnaire consisted of 20 items to identify EFL teachers' preferences in applying teaching style and choosing media. The questionnaire items were the modified version of some items in the one created by NERIS Analytic Limited in their website, 16personalities.com [7], and was designed specifically to identify EFL teachers' preferences. The link to the questionnaire was distributed via social media and online messenger to reach the targeted 75 English teachers.

Each teacher firstly filled general information including their name, institution they teach at, and also their MBTI -based personality type. Should they did not know their personality types yet, a link to the website (16personalities.com) consisted of free personality identification questionnaire was given. After the participants identified their personality types and filled the general information, they were asked to respond to 20 likert-scaled items related to teaching technique preferences.

Quenk stated that MBTI instrument should not be classified as a test since the word test implies right and wrong answers, while the questionnaire used to identify MBTI-based personality normally consists of perception-based statements that have no right or wrong answers [8]. Thus, the questionnaire used in this study, as well as the one in 16personalities.com are not tests but only survey instruments to classify personality types and teaching preferences of EFL teachers.

In-depth online interview was also applied to get more understanding regarding teachers' perspective towards their personality and its correlation to the teaching style or techniques they frequently applied. The interview was done through online text messenger and consists of openended questions that allowed the participants to respond.

\subsection{Data Analysis}

This study integrated both quantitative and qualitative approaches to acquire its data. Kothari identified quantitative approach concerned in documenting characteristics that could be counted. Meanwhile, qualitative approach in a research study was commonly used to emphasize subjective assessment of certain perspective or assumption. In most cases, observation and interview were used in such research design Kothari [9].

The study used survey questionnaire and MBTI test in 16personalities.com to obtain quantitative data. The use of MBTI in this study was to identify the personality types of all English teachers who took part as samples. After the personality types of each teacher were classified, survey was conducted by giving questionnaire consisted close-ended likert-scale 
items that would help in gathering information regarding EFL teachers' teaching preferences. Then responses of the given questionnaire were analyzed and checked with the traits of each personality based on MBTI charts and its mental functions. To determine if the items in the questionnaire were consistent in measuring the variables under investigation, the internal consistency of the items was measured through a correlation coefficient formula.

Frequency analysis was done to find out the percentage of different personality types from the total numbers of participants, and also to identify different responses from the scale of strongly disagree to strongly agree on each questionnaire item. Mode analysis was also conducted to find out the most personality types from the total numbers of participants, as well as the most answered responses from all questionnaire items.

To obtain qualitative data, in-depth interview had been done to some of the total English teachers participated in this study. The results of the interview were analyzed through Thematic Content Analysis to see the pattern of different personalities from the responses of each teacher during the interview.

\section{Results and Discussion}

After analyzing the responses of 75 (df: 75-2=73), English teachers as participants, the result of internal consistency measure shows that 17 out of 20 questionnaire items' validity are consistent and showing the correlation value that above the minimum standard $(0.23)$. Meanwhile, the other 3 items are found to be inconsistent. Given below are the results of correlation coefficient measure using correlation formula.

Table 1. Internal Consistency of Questionnaire Items.

\begin{tabular}{ccc}
\hline $\mathbf{Q}$ & $\mathbf{r} \mathbf{( 7 3 )}$ & Validity \\
\hline 1 & 0.5 & Valid \\
2 & 0.5 & Valid \\
3 & 0.4 & Valid \\
4 & 0.5 & Valid \\
5 & -0.03 & Not Valid \\
6 & 0.1 & Not Valid \\
7 & 0.4 & Valid \\
8 & 0.5 & Valid \\
9 & 0.4 & Valid \\
10 & 0.23 & Valid \\
11 & 0.6 & Valid \\
12 & 0.4 & Valid \\
13 & -0.09 & Not Valid \\
14 & 0.5 & Valid \\
15 & 0.6 & Valid \\
16 & 0.7 & Valid \\
17 & 0.5 & Valid \\
18 & 0.3 & Valid \\
19 & 0.6 & Valid \\
20 & 0.6 & Valid \\
\hline
\end{tabular}


Based on the validity check results, it has been decided that the analysis would only involve the 17 valid questionnaire items. While the other 3 items, that are not valid, would be considered to be analyzed further for the needs of another research.

The data collected from Google Form Questionnaires showed that the 75 English teachers who participated to respond to the questionnaire items had varied MBTI-based personality types. 13 of them were identified as INFJ (17.3\%), 10 others were ESFJ (13.3\%), 9 teachers were ENFJ (12\%), the other 8 were ENFP $(10.7 \%)$, while there were 6 teachers classified as INTJ (8\%). INTP $(5.3 \%)$, INFP (5.3\%), ISFP (5.3\%) and ISFJ (5.3\%) shared the same proportion with 4 teachers identified themselves as the types. There were 3 teachers classified as ENTJ (4\%) and 3 more as ENTP (4\%). There were 2 ISTJ (2.27\%) and 2 ISTP (2.27\%), while the rest of the types; ESTJ (1.3\%), ESFP (1.3\%), ESTP (1.3\%), had only 1 representative each.

Due to the uneven number of each type, the data are analyzed by firstly dividing the responses of different type into 16 groups of data based on the MyersBriggs Personality Types, then calculating the average value of each answer on the questionnaire items by each group of personalities. Although all types are mentioned, the analysis is focused on the personality types with at least 4 representatives (5\% of total samples). Thus, the given analysis and discussion are focused on INFJ, ESFJ, ENFJ, ENFP, INTJ, INFP, INTP, ISFJ, and ISFP.

The responses from each group of personalities towards the questionnaire items are varied. Although some personality types share similar perspective regarding several teaching beliefs that was delivered as survey items in the questionnaire, multifarious responses are also dominant. Based on the responses of the English teachers with different personality types, the following set of data was found, and analyzed.

Table 2. Results of Questionnaire Responses Based on Each Personality Type.

\begin{tabular}{|c|c|c|c|c|c|c|c|c|c|c|c|c|c|c|c|c|c|c|c|c|c|c|}
\hline MBTI & $\mathbf{P}$ & $\%$ & Q1 & Q2 & Q3 & Q4 & Q5 & Q6 & Q7 & Q8 & Q9 & Q10 & Q11 & Q12 & Q13 & Q14 & Q15 & Q16 & Q17 & Q18 & Q19 & Q20 \\
\hline INFJ & 13 & $17 \%$ & 3,9 & 4,5 & 3,8 & 4,3 & 2,8 & 3,2 & 4,3 & 3,8 & 4,6 & 3,3 & 4,3 & 4,4 & 2,8 & 4,2 & 4,5 & & & 3,4 & 4,2 & 4,5 \\
\hline ESFJ & 10 & $13 \%$ & 4,3 & 4,0 & 4,3 & 4,1 & 3,4 & 2,6 & 4,4 & 4,3 & 4,3 & 2,6 & 3,6 & 4,0 & 2,5 & 3,5 & 4,4 & 4,6 & 4,3 & 3,5 & 4,4 & 4,6 \\
\hline ENFJ & 9 & $12 \%$ & 3,9 & 4,8 & 4,6 & 4,9 & 2,2 & 2,3 & 4,1 & 4,4 & 4,3 & 3,0 & 4,6 & 3,7 & 2,8 & 4,0 & 4,2 & 4,4 & & 4,1 & 4,3 & 4,1 \\
\hline ENFP & 8 & $11 \%$ & 4,4 & 4,0 & 3,8 & 4,0 & 2,4 & 2,5 & 4,1 & 4,4 & 4,3 & 2,4 & 3,9 & 3,8 & 3,1 & 3,6 & 4,1 & 4,0 & 3,6 & 2,9 & 4,1 & 4,0 \\
\hline INTJ & 6 & $8 \%$ & 4,3 & 4,7 & 3,8 & 4,3 & 1,7 & 2,5 & 4,0 & 4,0 & 4,5 & 2,7 & 3,8 & 3,8 & 2,7 & 4,0 & 5,0 & 3,8 & 3,0 & 4,0 & 4,2 & 4,3 \\
\hline INFP & 4 & $5 \%$ & 4,3 & 3,5 & 4,0 & 4,5 & 2,3 & 2,5 & 3,3 & 3,8 & 3,3 & 3,8 & 4,5 & 3,0 & 2,8 & 4,0 & 4,3 & 4,3 & 4,0 & 3,0 & 2,5 & 4,3 \\
\hline INTP & 4 & $5 \%$ & 4,8 & 3,5 & 3,0 & 3,3 & 1,8 & 3,3 & 3,3 & 3,8 & 4,3 & 4,3 & 3,8 & 3,5 & 3,0 & 4,3 & 3,5 & 2,5 & 3,0 & 3,0 & 2,5 & 3,8 \\
\hline ISFJ & 4 & $5 \%$ & 4,3 & 4,0 & 3,3 & 3,8 & 2,3 & 2,8 & 4,5 & 2,5 & 3,3 & 3,0 & 4,5 & 3,8 & 3,5 & 3,8 & 4,0 & 3,8 & 3,5 & 2,8 & 3,8 & 4,5 \\
\hline
\end{tabular}




\begin{tabular}{|c|c|c|c|c|c|c|c|c|c|c|c|c|c|c|c|c|c|c|c|c|c|c|}
\hline ISFP & 4 & $5 \%$ & 4,8 & 4,5 & 4,5 & 3,8 & 2,8 & 2,8 & 4,8 & 4,0 & 4,0 & 4,0 & 2,8 & 4,5 & 3,0 & 4,3 & 4,8 & 3,5 & 3,3 & 3,5 & 4,5 & 4,5 \\
\hline ENTJ & 3 & $4 \%$ & 3,3 & 3,3 & 3,0 & 3,0 & 3,0 & 3,0 & 3,3 & 2,0 & 3,7 & 3,0 & 2,7 & 2,7 & 3,7 & 3,7 & 3,3 & 2,7 & 3,7 & 2,3 & 3,0 & 2,7 \\
\hline ENTP & 3 & $4 \%$ & 4,0 & 4,7 & 4,3 & 4,3 & 2,7 & 3,0 & 3,7 & 3,3 & 4,0 & 2,0 & 3,3 & 3,3 & 2,0 & 3,7 & 4,0 & 4,7 & 4,3 & 3,7 & 4,7 & 4,0 \\
\hline ISTJ & 2 & $3 \%$ & 4,5 & 4,5 & 3,0 & 4,5 & 2,0 & 4,0 & 4,5 & 2,5 & 4,0 & 2,5 & 4,5 & 4,5 & 4,5 & 4,5 & 5,0 & 5,0 & 5,0 & 4,5 & 5,0 & 5,0 \\
\hline ISTP & 2 & $3 \%$ & 3,0 & 5,0 & 4,5 & 3,0 & 2,0 & 2,0 & 4,0 & 2,5 & 4,0 & 2,0 & 3,0 & 4,0 & 3,0 & 3,5 & 4,5 & 3,0 & 3,5 & 3,5 & 4,0 & 5,0 \\
\hline ESFP & 1 & $1 \%$ & 4,0 & 4,0 & 2,0 & 4,0 & 2,0 & 1,0 & 5,0 & 5,0 & 4,0 & 5,0 & 5,0 & 4,0 & 4,0 & 5,0 & 4,0 & 4,0 & 4,0 & 2,0 & 2,0 & 4,0 \\
\hline ESTJ & 1 & $1 \%$ & 2,0 & 4,0 & 4,0 & 2,0 & 5,0 & 4,0 & 4,0 & 1,0 & 2,0 & 1,0 & 4,0 & 4,0 & 4,0 & 3,0 & 2,0 & 3,0 & 2,0 & 4,0 & 4,0 & 2,0 \\
\hline ESTP & 1 & $1 \%$ & 3,0 & 5,0 & 4,0 & 4,0 & 2,0 & 1,0 & 4,0 & 4,0 & 4,0 & 3,0 & 4,0 & 4,0 & 3,0 & 4,0 & 4,0 & 5,0 & 4,0 & 2,0 & 4,0 & 3,0 \\
\hline
\end{tabular}

From the given table, it can be seen that the 75 participants have varied personality types with INFJ as the most dominant (17\%) and ESFP, ESTJ, and ESTP with the least (1\%). The responses to each questionnaire item have been calculated into average value of each type as it can be seen in column Q1 to Q20. Starting with the first questionnaire item, which is intended to identify teachers' preference in sharing trivial knowledge as pre-learning activity, the data show common perception where most teachers, except ISTP, ESTJ, and ESTP, tend to share trivial information to grab students' attention at the beginning of their classes.

For questionnaire item number 2, about engaging students to participate in early discussion before main lesson, only teachers with ENTJ as their personality type who prefer giving lecture and do not expect for responses from the students. Meanwhile, ENFJ and ESTP become the type with the most expectation towards students' responses among other types.

Preference in designing and applying language game is questioned in item number 3. The responses show some variations in teachers' perception. Most teachers agree that they like to apply language game to begin English class, while some teachers with INTP and ENTJ personality type tend to be neutral. One ESTJ teacher surprisingly dislikes the idea of using game in English class.

In classroom division, most teachers agreed to have small groups during some activities such as discussion or project. Meanwhile, 8 teachers do not like the idea of creating small groups when it comes to discussion or project making.

Although it was proven to be slightly not consistent, responses towards item number 5 show intriguing trend. Most teachers that participated in responding the questionnaire item have similar disagreement when coming to their versatility in adapting to the situation, and modifying their lesson plan. It is only ESTJ who states that he/she would stick to his/her original plan no matter what situation is being faced during the lesson. For item number 6 , most 
teachers disagree that having more lecture is more important than conducting class discussion. However, ISTJ and ESTJ against the dominant population, and believe that having conceptual explanation about certain theories is more essential.

Responses to item number 7 are generally coming to common belief that students are expected to be actively asking question and discuss after teachers explain some concepts. However, different perspective occurs in responses to item number 8 where teachers with ISFJ and ENTJ as their personality do not expect and try to avoid their students from having off topic discussion during English lesson, although the students actively use English. Almost all teachers who are classified as ENFP, INTJ and INFJ do not have any problem with off topic discussion.

Questionnaire item number 9 identifies teachers' preference in language correction. Most teachers agree that content and context of the language production is more important than the structure of the language produced by the students. However, a small percentage of English teachers believe that grammar checking is also essential. For item number 10, varied responses were gathered. Most personality types including ENFP, INTJ, ESFJ and ENTJ prefer to have planned power point slides or ready-to-use materials to be written on white board. However, some other teachers with other types of personality would like to use editable slides or openended material that can be modified during the lesson such as some empty slides.

Responses to item number 11 show common belief of English teachers in giving projectbased assignment instead of theoretical exercises. It is only the minority population of teachers with ENTJ as their personality who believe that theoretical-based assignment is more effective. The next responses, addressed to item number 12 , show that almost every type agrees to give production tasks such as writing and video making outside the regular class schedule. However, teachers that are classified as ENTJ, ISFP, and ENTP believe that it is not an issue to give production project during the lesson.

Number 13 is another invalid questionnaire item. However, the responses toward this statement regarding choice of topic and media are quite highly varied. The top five types; INFJ, ESFJ, ENFJ, ENFP, and INTJ (61\% of the total participants) disagree with the statement that indicates their preferences in topic are mostly driven by personal perspective. However, the other types put their side on neutral, or even agree, although none of them choose strongly agree. Responses to item number 14 show quite similar agreement among the teachers with different personality types. They believe that sharing resourceful material in the internet is necessary.

Responses to item number 15 also indicates beliefs of most teachers regarding language production that is not only based on test results, but also can be seen throughout the process of learning, as well as informal interactions among peers in the classroom. Only teachers with the personality types of INTP, ENTJ, and ESTJ put neutral as their overall perspective.

Responses to item number 16 and 17, which talk about media usage such as videos, and also animated graphic show that almost all types prefer to include such interactive modality except some teachers with INTP, ESTJ and ENTJ personalities. Meanwhile, responses towards item number 18, 19, and 20, which are intended to see teachers' perspective in managing the class, show some varied feedbacks. Apart from the majority, some teachers who are classified as ENFP, INTP, INFP and ISFJ prefer to not roam around the class after assignment or task is given. However, ENFP and INTP still quietly observe the performance of the students, and the process during the task, while ISFJ, along with INFP, are most likely to be idle and wait from afar. The other types believe that active observation and roaming around the class are important part of lesson while the students are doing task. 


\subsection{Responses towards Interview}

Due to the recent limitation in meeting people and the policy of social distancing, some teachers who participated in responding to the questionnaire were interviewed towards online messenger. The interviewed teachers are 2 INFJ, 2 ENFP, 1 INTJ, 1 ISFJ and 1 INTP. They were asked questions regarding their personal beliefs that are related to their personality types, in relation to their profession as teacher who have experience in teaching at senior high school level.

The answers of teachers from different personality groups show some significant differences in their belief, while teachers with similar type tend to share common thought regarding several beliefs in EFL teaching. For instance, the 2 INFJ, ISFJ and the INTJ teacher prefer obedient group of students who attentively listening, instead of the highly critical group of students that have probability of actively ask and argue. Apart from their prior belief, teachers under the personality of INFJ, INTP, and INTJ tend to expect their students to be cooperative and obedient, but at the same time, do not mind having intense discussion with the students whenever needed. On the other hand, ENFP, and INTP demand the students to be more versatile and critical. They do not like passive and overly obedient students as it will limit their choices of strategies during the lesson. ISFJ, surprisingly, may adapt to any situation although they prefer the obedient and cooperative one.

Further responses show that different teachers have their personal preference in the type of students they would like to teach and the ones they find difficult to handle in the classroom. INFJ and INTJ tend to avoid ENTP and expect to have ESFP, and other introverted types such as ISFJ, ISTP, and INFP. Meanwhile, teachers with the personality of ENFP do not expect ISFJ in their class, and prefer to teach a group consists of INFJ, INFP, ENFP, and ESTP. Overall, they find MBTI interesting and useful in identifying their own characteristics, as well as their students, and other teachers as their colleagues.

\section{Conclusion and Recommendation}

Based on the findings and discussions, it can be concluded that MBTI play a significant role in driving English teachers' perception and beliefs about EFL teaching. However, it can also be seen that different teachers who are classified in different personality types may have some common beliefs when it comes to something general as it has been analyzed above.

As the field of personality types and EFL teaching is still very broad, further research needs to be done to discover new findings related to the particular field. Some possible studies to be conducted ahead include the case study to discover deeper correlations among EFL teaching and each personality type, or the study that analyzed personality types influences in EFL learners.

\section{References}

[1] Russell, A. \& Avgerinou, M. 2007. Using Myers-Briggs Personality Preferences to Understand Different Online Teaching Styles.

[2] Myers, I. B. 1998. Introduction to Types. CCP, Inc. Mountain View, California.

[3] Kise, Jane A.G. 2005. Coaching Teachers for Change: Using the Concepts of Psychological Type to Reframe Teacher Resistance. Journal of Psychological Type. Issue 6, 47-58.

[4] Rushton, S., Mariano, J. M., and Wallace, T. L. 2012. Program Selection among Pre-Service Teachers: MBTI Profiles within a College of Education. SciRes Literature. Vol.2, No.1, 1-8. 
[5] Behnam, B. \& Bayazidi, M. 2013. The relationship between personality types and teaching styles in Iranian adult TEFL context. Global Journal of Foreign Language Teaching. 02 (2013), 21-32.

[6] Altan, M. Z. 2018. Psychological Type and Teaching: A Case of Prospective ELT Teachers. International Journal of Languages' Education and Teaching. Vol.6, Issue 2, 295-308.

[7] Limited, N. A. "It's so incredible to finally be understood." Retrieved August 16, 2020, from https://www.16personalities.com/.2011.

[8] Quenk, N. L. 2009. Essentials of Myers-Briggs Type Indicator Assessment. John Wiley \& Sons, Inc. US.

[9] Kothari, C.R. 2004. Research Methodology: methods and techniques. New Age International (P) Limited. India. 